\title{
Molecular modeling and experimental studies on structure and NMR parameters of 9-benzyl-3,6-diiodo-9H-carbazole
}

\author{
Klaudia Radula-Janik • Teobald Kupka • \\ Krzysztof Ejsmont • Zdzisław Daszkiewicz • \\ Stephan P. A. Sauer
}

Received: 9 December 2014/Accepted: 16 December 2014/Published online: 11 January 2015

(C) The Author(s) 2015. This article is published with open access at Springerlink.com

\begin{abstract}
A combined experimental and theoretical study has been performed on 9-benzyl-3,6-diiodo-9H-carbazole. Experimental X-ray $(100.0 \mathrm{~K})$ and room-temperature ${ }^{13} \mathrm{C}$ nuclear magnetic resonance (NMR) studies were supported by advanced density functional theory calculations. The non-relativistic structure optimization was performed and the ${ }^{13} \mathrm{C}$ nuclear magnetic shieldings were predicted at the relativistic level of theory using the zeroth-order regular approximation. The changes in the benzene and pyrrole rings compared to the unsubstituted carbazole or the parent molecules were discussed in terms of aromaticity changes using the harmonic oscillator model of aromaticity and the nucleus independent chemical shift indexes. Theoretical relativistic calculations of chemical shifts of carbons $\mathrm{C} 3$ and C6, directly bonded to iodine atoms, produced a reasonable agreement with experiment (initial deviation from experiment of 41.57 dropped to $5.6 \mathrm{ppm}$ ). A good linear correlation between experimental and theoretically predicted structural and NMR parameters was observed.
\end{abstract}

Electronic supplementary material The online version of this article (doi:10.1007/s11224-014-0554-8) contains supplementary material, which is available to authorized users.

K. Radula-Janik · T. Kupka ( $₫) \cdot$ K. Ejsmont · Z. Daszkiewicz Faculty of Chemistry, Opole University, 48, Oleska Street, 45-052 Opole, Poland

e-mail: teobaldk@gmail.com

S. P. A. Sauer $(\square)$

Department of Chemistry, University of Copenhagen,

Universitetsparken 5, 2100 Copenhagen, Denmark

e-mail: sauer@kiku.dk

\section{Graphical Abstract}

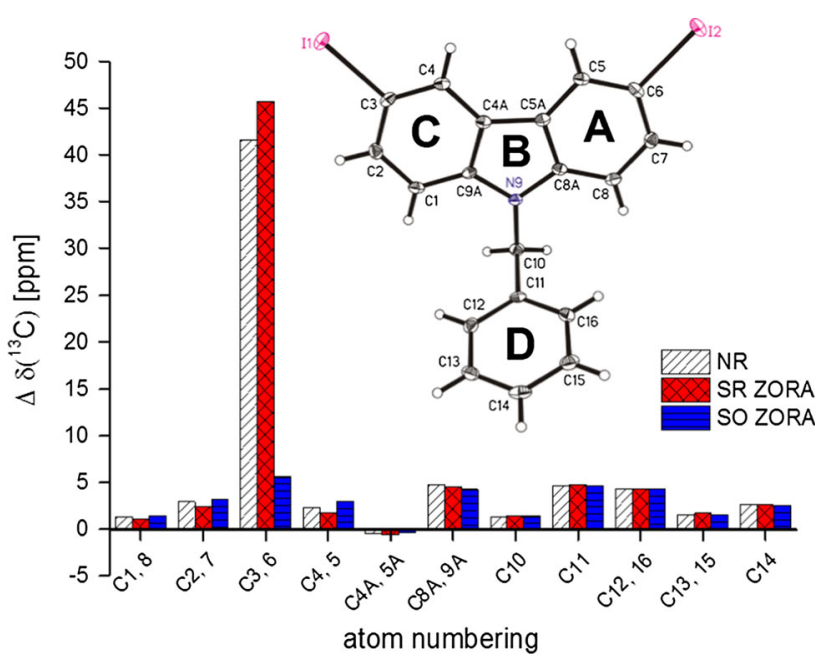

Keywords 9-Benzyl-3,6-diiodo-9H-carbazole $\cdot$ X-ray structure $\cdot{ }^{13} \mathrm{C}$ NMR spectra $\cdot$ ZORA $\cdot$ GIAO NMR calculations $\cdot$ HOMA $\cdot$ NICS

\section{Introduction}

Carbazole and its derivatives have been of special interest because of their unique photoconductive [1] and optical properties [2]. Polymers containing carbazole moiety are very promising new materials [3] and are widely used in electronics and photonics [4-7]. Due to their interesting properties, the chemistry of carbazole derivatives has been studied at length [8-10]. One of the most common carbazole derivatives applied in electrophotographic [8] is poly ( $N$-vinylcarbazole). The 3,6- and 2,7-substituted carbazole 
derivatives are currently among the most widely studied materials [11-15]. It is known that the presence of heavy atoms $(\mathrm{Cl}$ and $\mathrm{Br})$ decreases the relative quantum yield of fluorescence and increases phosphorescence in the carbazole derivatives [16]. Bonesi [17] observed the same effect in carbazole modified by $\mathrm{Cl}$ and $\mathrm{Br}$ at positions 3 and 3, 6 in a solid matrix. Finally, in a work of Safoula [18] an increase in conductivity by molecular doping with iodine was observed.

Experimental nuclear magnetic resonance (NMR) studies are widely used to characterize the geometrical and electronic structure of isolated compounds, their solutesolute and solute-solvent interactions in solution. Nowadays, the assignment of experimental spectra is often supported by molecular modeling of the relevant NMR parameters [19-21], as it is possible to predict satisfactory chemical shifts for several different nuclei including ${ }^{13} \mathrm{C}$, ${ }^{17} \mathrm{O},{ }^{15} \mathrm{~N}$, and ${ }^{19} \mathrm{~F}[19,22-25]$ using density functional theory (DFT) calculations in combination with gauge including atomic orbitals (GIAOs [26, 27]) and employing the Becke three-parameter, Lee-Yang-Parr (B3LYP [27, 28]) or the hybrid half-and-half (BHandHLYP) exchange correlation functionals [29]. Several NMR reports on the simplest carbazoles are available [30-33]. However, systematic studies of the correlation between the molecular structure of carbazoles and their NMR parameters are lacking in the literature. The presence of a fairly heavy nucleus (here iodine) in a molecule affects the NMR properties of the neighboring light atom (close in space or directly connected $\mathrm{H}, \mathrm{C}, \mathrm{N}$ atoms). This effect was described by Pyykkö et al. [34] as the heavy-atom-on-lightatom (HALA) effect. Ziegler, Autschbach and Arcisauskaite [35-41] reported on several relativistic calculations of NMR shieldings. In the work of Pecul et al. [42] the importance of inclusion of the HALA effect on ${ }^{13} \mathrm{C}$ shielding constants in organomercury compounds and halogen derivatives was discussed. They observed large spin-orbit (SO) contributions to the HALA effects in the halogen substituted compounds, which were well reproduced using zeroth-order regular approximation with SO coupling (SO ZORA [43-45]) while these effects could not be recovered using relativistic effective core potentials (ECP [46]) on the halogen atoms. The study of Wodyński and Pecul [47] described the influence of heavy atom on the spin-spin coupling constants between two light nuclei in organometallic compounds and halogen derivatives.

Another main factor related to the structural and electronic parameters of carbazoles and resulting in their different chemical properties is aromaticity. This chemical property can be analyzed in several ways: via structurally (harmonic oscillator model of aromaticity), electronically (PDI-para-delocalization index), and magnetically (NICS) based indices. The work of Poater et al. [48] showed a clear divergence between the structural, electronic, and magnetic measures, so it is important to use different aromaticity indexes to quantify this property. The HOMA is a structurally based measure of aromaticity. It was defined by Kruszewski and Krygowski [49, 50] as

$H O M A=1-\frac{\alpha}{n} \sum_{i=1}^{n}\left(R_{o p t}-R_{i}\right)^{2}$,

where $n$ is the number of included bonds with bond lengths $R_{i}$, and $\alpha$ is an empirical constant chosen in such a way that HOMA $=0$ for a model non aromatic system, and HOMA $=1$ for a system with all bonds equal to an optimal value $R_{\mathrm{opt}}$, assumed to be achieved for fully aromatic systems. The HOMA index has been found to be among the most effective structural indicators of aromaticity. Another way to show the aromaticity of a compound is the widely employed nucleus independent chemical shift (NICS), which was defined by Schleyer et al. [51] as the negative value of the absolute shielding computed at the ring center, or at some other interesting geometrical point of the system. In common use, there are three variants: $\mathrm{NICS}(0)$ calculated at the ring plane, NICS(1) calculated $1 \AA$ above the plane, and its zz-tensor component, $\mathrm{NICS}(1)_{\mathrm{zz}}$, where the $z$-axis is a normal to the plane. Rings with large negative NICS values are considered to be aromatic and the more negative the NICS value is the more aromatic the rings are.

Keeping in mind the above facts, we aimed to synthesize and characterize a very specific carbazole derivative containing two iodo-substituents. Its crystal structure and NMR spectra are not yet described in the literature. This paper presents thus the first report on crystal structure of 9-benzyl-3,6-diiodo-9H-carbazole and its ${ }^{13} \mathrm{C} \quad \mathrm{NMR}$ parameters in $\mathrm{CDCl}_{3}$ solution. We compare the experimental low temperature X-ray $(100.0 \mathrm{~K})$ and room-temperature NMR data with the DFT-calculated geometry of a single molecule in the gas phase and its carbon shifts calculated using standard non-relativistic and the relativistic ZORA approach. The changes in aromaticity in 9-benzyl3,6-diiodo-9H-carbazole compared to free carbazole, benzene, and pyrrole are also discussed via the structural HOMA and magnetic NICS measures.

\section{Experimental}

\section{Synthesis}

3,6-Diiodo- $9 H$-carbazole was obtained according to the procedure described by Chuang et al. [52]. A solution containing $16.7 \mathrm{~g}(0.1 \mathrm{~mol})$ of $9 H$-carbazole, $21.6 \mathrm{~g}$ $(0.13 \mathrm{~mol})$ of $\mathrm{KI}, 21.4 \mathrm{~g}(0.1 \mathrm{~mol})$ of $\mathrm{KIO}_{3}, 150 \mathrm{~cm}^{3}$ of acetic acid, and $15 \mathrm{~cm}^{3}$ of water was heated for $48 \mathrm{~h}$ on a water bath at $80{ }^{\circ} \mathrm{C}$. After cooling to the room temperature, 
the precipitate was filtered off and washed with water, saturated $\mathrm{Na}_{2} \mathrm{CO}_{3}$ solution, and methanol. The crude product was crystallized from toluene. The yield was $25 \mathrm{~g}$ of 3,6-diiodo- $9 \mathrm{H}$-carbazole $\quad\left(\mathrm{mp}=206-207^{\circ} \mathrm{C} ; \quad \mathrm{Ed}\right.$. $60 \%)$.

The preparation of 9-benzyl-3,6-diiodo-9H-carbazole is shown in Scheme 1.

To the intensively stirred solution of $2 \mathrm{~g}(4.77 \mathrm{mmol})$ of 3,6-diiodo- $9 H$-carbazole in DMSO $(30 \mathrm{ml})$ and tetrabutylammonium iodide $(0.2 \mathrm{~g}), 50 \%$ aqueous $\mathrm{KOH}$ solution $(2 \mathrm{ml})$ was added and treated dropwise with $1.9 \mathrm{~cm}^{3}$ $(16 \mathrm{mmol})$ of benzyl bromide in DMSO $(10 \mathrm{ml})$. After two hours the mixture was poured into water $(100 \mathrm{ml})$. The precipitate was dissolved in methylene chloride $(30 \mathrm{ml})$ and dried with anhydrous $\mathrm{MgSO}_{4}$. After evaporation of the solvent, the residue $(2.35 \mathrm{~g})$ was crystallized from $20 \mathrm{~cm}^{3}$ of acetone. The yield was $2.2 \mathrm{~g}$ of 9-benzyl-3,6-diiodo- $9 \mathrm{H}$ carbazole $\left(\mathrm{mp}=175-176{ }^{\circ} \mathrm{C}\right.$; Ed. $\left.90.5 \%\right)$.

The crystals suitable for X-ray analysis of 9-benzyl-3,6diiodo- $9 \mathrm{H}$-carbazole were obtained by slow evaporation of a saturated solution in chloroform.

\section{Characterization}

The single crystals of 9-benzyl-3,6-diiodo-9H-carbazole were used for data collection at 100.0(1) K on a four-circle Oxford Diffraction Xcalibur diffractometer equipped with a two-dimensional area CCD detector with the graphite monochromatised $\mathrm{MoK} \alpha$ radiation $(\lambda=0.71073 \AA)$ and the $\omega$-scan technique. Integration of the intensities and correction for Lorenz and polarization effects were performed using the CrysAlis RED software [53]. Crystal structures were solved by direct methods and refined by a full-matrix least-squares method on $F^{2}$ using the SHELXL97 program [54]. Complete crystallographic details are available as a supplementary material, and have been deposited at the Cambridge Crystallographic Data Centre (CCDC 990604) CCDC [55]. Any request to the CCDC for this material should quote the full literature citation. The room-temperature ${ }^{13} \mathrm{C}$ NMR spectra in $\mathrm{CDCl}_{3}$ solution were measured using Bruker Ultrashield $400 \mathrm{MHz}$ NMR spectrometer operating at $100.663 \mathrm{MHz}$ for carbon nuclei at ambient temperature and referenced to tetramethylsilane (TMS) as internal standard.

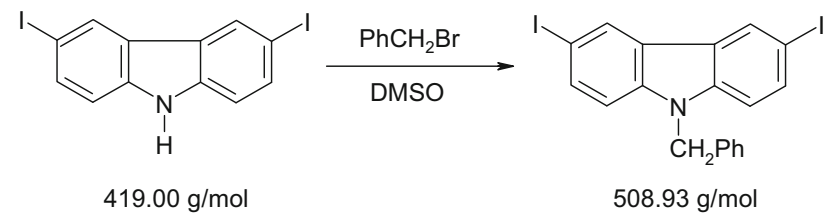

Scheme 1 Synthesis of 9-benzyl-3,6-diiodo-9H-carbazole
Theoretical calculations

The geometric parameters of the isolated molecule were obtained from an unconstrained optimization using the B3LYP density functional $[27,28,56]$ and a flexible $6-311++\mathrm{G}(3 \mathrm{df}, 2 \mathrm{pd})$ basis set for $\mathrm{C}, \mathrm{N}$ and $\mathrm{H}$, and the smaller $6-311 \mathrm{G}^{* *}$ basis set for iodine. The subsequent vibrational analysis at the same level of theory showed no imaginary frequencies indicating a true energy minimum. These traditional non-relativistic calculations were carried out using Gaussian 09 [57]. In the subsequent steps, the non-relativistic geometry has been used both for typical non-relativistic shielding calculations with the BHandHLYP half-and-half hybrid functional [29] and for the relativistic shielding calculations employing the zeroth-order regular approximation Hamiltonian, including the SO coupling term (SO ZORA) [58]. For consistence, all NMR parameters were obtained with Amsterdam density functional (ADF) program [59]. In this case, we employed the DZP-, TZ2P-, and QZ4P STO-type basis sets. However, we are aware that slightly better agreement between theoretical and experimental NMR parameters could be obtained using optimized structures at the same level of theory [60]. Theoretical chemical shifts (in $\mathrm{ppm}$ ) were referenced to benzene calculated at the same level of theory.

The HOMA and NICS indexes of aromaticity were calculated in Gaussian 09 at the same level as the geometry optimization.

\section{Results and discussion}

\section{Crystal structure}

The molecular structure of 9-benzyl-3,6-diiodo-9H-carbazole, the atomic numbering and ring labeling schemes are presented in Fig. 1. The packing arrangement in the crystal state is presented in Fig. 2. The molecular structure of 9-benzyl-3,6-diiodo-9H-carbazole consists of two units: the carbazole unit containing atoms $\mathrm{C} 1-\mathrm{C} 9 \mathrm{~A}$ and the benzyl unit containing atoms $\mathrm{C} 10-\mathrm{C} 16$.

The crystal data measured at $100 \mathrm{~K}$ and refinement parameters are summarized in Table 1 . The interatomic distances between iodine atoms in neighboring molecules are given in Table 2 and selected bond lengths in Table 3. For brevity, all experimental bond distances, bond angles, and torsion angles within this compound are given in Tables S1, S2, and S3 in the Supplementary Material. The value of iodine-iodine distance coincides well with their van der Waals radius proposed by Bondi (1.98 $\AA$ [61]) or Bastanov (2.1 $\AA$ $[62,63])$. Thus, the intermolecular I $\cdots I$ I contact of 3.9558(3) $\AA$ in the crystal structure of the title compound is about twice the iodine van der Waals radius (see Table 2; Fig. 2). 


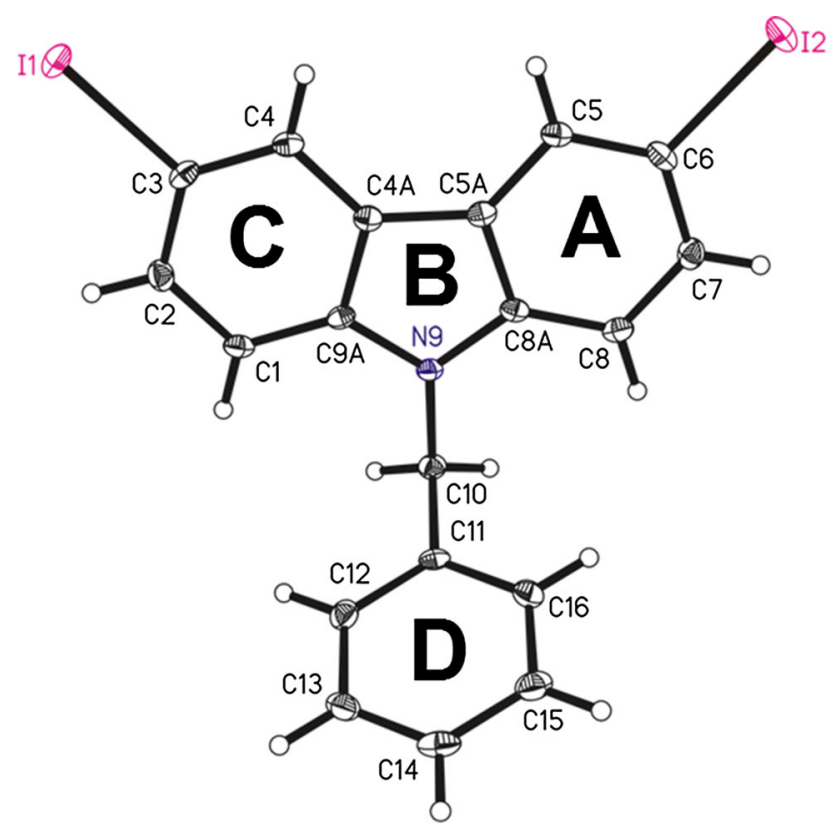

Fig. 1 The molecular structure of 9-benzyl-3,6-diiodo-9H-carbazole, showing the atom numbering scheme and the ring labeling. Displacement ellipsoids are drawn at the $50 \%$ probability level

It is well known that X-ray crystallography determines accurately bond lengths between non-hydrogen atoms and significantly underestimates $\mathrm{C}-\mathrm{H}$ bonds [64]. This is also apparent from Table S1. Therefore, we will limit the discussion of theoretical bond lengths to $\mathrm{C}-\mathrm{C}, \mathrm{C}-\mathrm{N}$, and $\mathrm{C}-\mathrm{I}$ only (see Table 3). All measured bond lengths and angles are within normal ranges and fairly similar to distances reported earlier for 9-benzyl-9H-carbazole X-ray structure [65] (see Table 3). For better illustration of the quality of predictions in the gas phase, we compared in Fig. 3 the theoretical (non-relativistic) bond lengths with experimental values obtained from X-ray measurement at low temperature. A good agreement between theoretical and experimental interatomic distances of 9-benzyl-3,6-diiodo$9 H$-carbazole is apparent from a perfect linear correlation between theory and experiment $(y=1.0415 x-0.0535$, $R^{2}=0.9998$ ), see Fig. 3).

The structural parameters obtained at the ZORA (B3LYP/DZP/TZP level of theory) are of similar accuracy to the results of the non-relativistic calculations, but they are more time-consuming and we will not consider them in future studies. The differences between theoretical and experimental $\mathrm{C}-\mathrm{C}$ and $\mathrm{C}-\mathrm{N}$ bond lengths are in the range of $0.013-0.001 \AA$. For the $\mathrm{C}-\mathrm{I}$ bond the difference is higher (in the range of 0.03-0.04 $\AA$ ). All geometric data for the studied carbazole derivative correlate also well with the corresponding values found in the crystal structure of the non-halogenated 9-benzyl-9H-carbazole [65] (see Table 3).
Fig. 2 A packing diagram for 9-benzyl-3,6-diiodo-9Hcarbazole

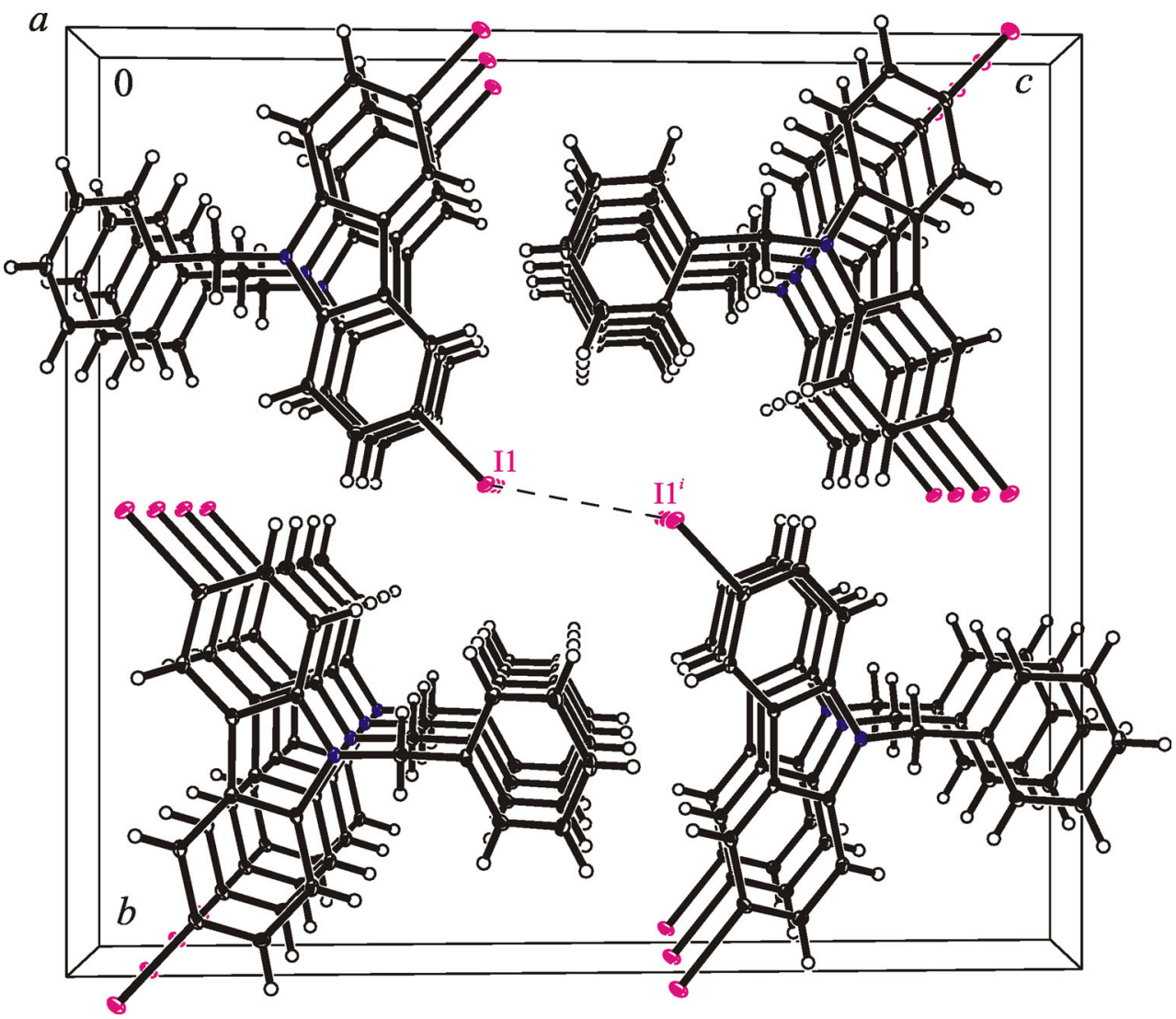


Table 1 Crystallographic data for 9-benzyl-3,6-diiodo-9H-carbazole at $100 \mathrm{~K}$

\begin{tabular}{|c|c|}
\hline \multicolumn{2}{|l|}{ 9-Benzyl-3,6-diiodo-9H-carbazole } \\
\hline Chemical formula & $\mathrm{C}_{19} \mathrm{H}_{13} \mathrm{I}_{2} \mathrm{~N}$ \\
\hline$M_{\mathrm{r}}$ & 509.10 \\
\hline Cell setting, space group & Monoclinic, $P 2_{1} / n$ \\
\hline Temperature $(\mathrm{K})$ & $100.0(1)$ \\
\hline$a, b, c(\AA)$ & $4.20240(10), 18.8796(3), 20.3862(3)$ \\
\hline$\beta\left(^{\circ}\right)$ & $92.8680(10)$ \\
\hline$V\left(\AA^{3}\right)$ & $1615.41(5)$ \\
\hline$Z$ & 4 \\
\hline$D_{\mathrm{x}}\left(\mathrm{mg} \mathrm{m}^{-3}\right)$ & 2.093 \\
\hline Radiation type & $\operatorname{MoK} \alpha$ \\
\hline$\mu\left(\mathrm{mm}^{-1}\right)$ & 3.889 \\
\hline Crystal size (mm) & $0.30 \times 0.28 \times 0.26$ \\
\hline No. of measured, independent, and observed reflections & $9726 / 2806 / 2707$ \\
\hline$R_{\text {int }}$ & 0.0146 \\
\hline$(\sin \theta / \lambda)_{\max }\left(\AA^{-1}\right)$ & 0.595 \\
\hline$R\left[F^{2}>2 \sigma\left(F^{2}\right)\right], w R\left(F^{2}\right), S$ & $0.0186,0.0405,1.303$ \\
\hline No. of reflections & 2,806 \\
\hline No. of parameters & 200 \\
\hline No. of restrains & 0 \\
\hline $\mathrm{H}$-atom treatment & $\mathrm{H}$ atoms treated by a mixture of independent and considered refinement \\
\hline Weighting scheme & $w=1 /\left[\sigma^{2}\left(F_{\mathrm{o}}^{2}\right)+(0.0131 P)^{2}+1.9288 P\right]$ where $P=\left(F_{o}^{2}+2 F_{\mathrm{c}}^{2}\right) / 3$ \\
\hline$\Delta \rho_{\max }, \Delta \rho_{\min }\left[\mathrm{e} \AA^{-3}\right]$ & $0.393,-0.379$ \\
\hline
\end{tabular}

Table 2 Experimental iodine-iodine distance (in $\AA$ ) for 9-benzyl3,6-diiodo- $9 H$-carbazole in the solid state at $100 \mathrm{~K}$

\begin{tabular}{lll}
\hline $\mathrm{D}-\mathrm{I} \cdots \mathrm{A}$ & $d(\mathrm{D}-\mathrm{I})$ & $d(\mathrm{I} \cdots \mathrm{A})$ \\
\hline $\mathrm{C}(3)-\mathrm{I}(1) \cdots \mathrm{I}(1)^{\mathrm{i}}$ & 2.103 & $3.9558(3)$
\end{tabular}

Symmetry transformations used to generate equivalent atoms: $\mathrm{i}=1-x, 2-y,-z$

\section{${ }^{13} \mathrm{C}$ NMR chemical shift}

All experimental and calculated ${ }^{13} \mathrm{C}$ chemical shifts of the studied carbazole are collected in Table 4. It is apparent that a very significant HALA effect of about $-42 \mathrm{ppm}$ is only present for the $\mathrm{C} 3$ and $\mathrm{C} 6$ carbons directly bond to iodine atoms.

Thus, the non-relativistic calculations of $\mathrm{C} 3$ and $\mathrm{C} 6$ chemical shifts lead to significant errors with a root mean square deviation (RMS) of $12.85 \mathrm{ppm}$ (for SO ZORA calculations RMS $=3.34 \mathrm{ppm}$, see Table 4 and Fig. 4). It is also apparent from Fig. 4 that the spin-orbit effects played a major role in the calculations of chemical shifts of carbon atoms directly attached to the halogen atom (here iodine). The observed HALA effects are very close to earlier results for halogen-substituted carbon atoms $[15,35$, 42]. The other carbons, however, do practically not feel the presence of the heavy halogen atoms.

\section{HOMA and NICS indexes}

The calculated HOMA and NICS values are gathered in Table 5. HOMA indexes were calculated from Equation (1) using $\alpha=257.7$ and $R_{\mathrm{opt}}(\mathrm{CC})=1.388 \AA$ [66] and bond lengths from B3LYP/6-311++G(3df,2pd) optimized geometries. For comparison, the corresponding HOMA values for benzene and pyrrole, calculated at the same level of theory are 0.998 and 0.772 . The most aromatic ring within the studied molecule is the benzyl unit $(\mathrm{D})$ : HOMA $=0.996$. The two benzene rings of the carbazole moiety ( $\mathrm{A}$ and $\mathrm{C}$ ) are very similar $(0.960$ and 0.962$)$. The aromaticity of these rings is higher than in the parent unsubstituted carbazole molecule (HOMA $=0.919)$. The least aromatic is the pyrrolic unit (ring B). In comparison to the parent pyrrole, the five-membered ring B is significantly less aromatic (0.446) than in the pyrrole molecule $(0.772)$ or in the unsubstituted carbazole (0.679).

Apart from HOMA, in Table 5 are also gathered the results for the three variants of the NICS parameter, 
Table 3 Comparison of selected geometric data for 9-benzyl-3,6-diiodo-9Hcarbazole ( $\AA$ ) and 9-benzyl-9Hcarbazole $(\AA)$ obtained from $\mathrm{X}$-ray measurements at $100 \mathrm{~K}$ and calculated via nonrelativistic (NR) B3LYP/6$311++\mathrm{G}(3 \mathrm{df}, 2 \mathrm{pd}) / 6-311 \mathrm{G}^{* *}$ and relativistic ZORA/DZP/ TZP geometry optimizations

RMS values are marked using bold font

\begin{tabular}{|c|c|c|c|c|}
\hline Bond & X-ray & NR DFT & ZORA DFT & 9-Benzyl-9H-carbazole (X-ray) $[65]$ \\
\hline $\mathrm{I}(1)-\mathrm{C}(3)$ & $2.103(3)$ & 2.135 & 2.135 & - \\
\hline $\mathrm{I}(2)-\mathrm{C}(6)$ & $2.097(3)$ & 2.135 & 2.135 & - \\
\hline $\mathrm{C}(1)-\mathrm{C}(2)$ & $1.384(4)$ & 1.391 & 1.387 & $1.383(5)$ \\
\hline$C(1)-C(9 A)$ & $1.391(4)$ & 1.395 & 1.389 & $1.04(3)$ \\
\hline$C(2)-C(3)$ & $1.401(4)$ & 1.403 & 1.398 & $1.396(4)$ \\
\hline $\mathrm{C}(3)-\mathrm{C}(4)$ & $1.376(4)$ & 1.389 & 1.383 & $1.380(5)$ \\
\hline $\mathrm{C}(4)-\mathrm{C}(4 \mathrm{~A})$ & $1.397(4)$ & 1.398 & 1.394 & $1.395(4)$ \\
\hline $\mathrm{C}(4 \mathrm{~A})-\mathrm{C}(9 \mathrm{~A})$ & $1.414(4)$ & 1.417 & 1.411 & $1.410(4)$ \\
\hline$C(4 A)-C(5 A)$ & $1.444(4)$ & 1.447 & 1.443 & $1.442(4)$ \\
\hline $\mathrm{C}(5 \mathrm{~A})-\mathrm{C}(5)$ & $1.397(4)$ & 1.398 & 1.413 & $1.398(4)$ \\
\hline$C(5 A)-C(8 A)$ & $1.413(4)$ & 1.418 & 1.413 & 1.401(4) \\
\hline$C(5)-C(6)$ & $1.378(4)$ & 1.389 & 1.383 & $1.372(4)$ \\
\hline$C(6)-C(7)$ & $1.402(4)$ & 1.403 & 1.397 & $1.401(4)$ \\
\hline$C(7)-C(8)$ & $1.385(4)$ & 1.391 & 1.387 & $1.377(4)$ \\
\hline$C(8)-C(8 A)$ & $1.393(4)$ & 1.396 & 1.389 & $1.398(4)$ \\
\hline $\mathrm{C}(8 \mathrm{~A})-\mathrm{N}(9)$ & $1.387(3)$ & 1.390 & 1.383 & $1.391(4)$ \\
\hline $\mathrm{N}(9)-\mathrm{C}(9 \mathrm{~A})$ & $1.388(3)$ & 1.389 & 1.383 & $1.381(4)$ \\
\hline $\mathrm{N}(9)-\mathrm{C}(10)$ & $1.458(3)$ & 1.451 & 1.443 & $1.458(4)$ \\
\hline $\mathrm{C}(10)-\mathrm{C}(11)$ & $1.512(4)$ & 1.523 & 1.517 & $1.509(4)$ \\
\hline $\mathrm{C}(11)-\mathrm{C}(12)$ & $1.390(4)$ & 1.395 & 1.390 & 1.393(4) \\
\hline $\mathrm{C}(11)-\mathrm{C}(16)$ & $1.392(4)$ & 1.399 & 1.394 & $1.384(4)$ \\
\hline $\mathrm{C}(12)-\mathrm{C}(13)$ & $1.390(4)$ & 1.395 & 1.390 & $1.386(4)$ \\
\hline $\mathrm{C}(13)-\mathrm{C}(14)$ & $1.385(4)$ & 1.393 & 1.388 & $1.379(5)$ \\
\hline$C(14)-C(15)$ & $1.386(4)$ & 1.395 & 1.387 & $1.379(5)$ \\
\hline$C(15)-C(16)$ & $1.388(4)$ & 1.393 & 1.390 & $1.387(4)$ \\
\hline RMS & & 0.012 & 0.012 & 0.073 \\
\hline
\end{tabular}

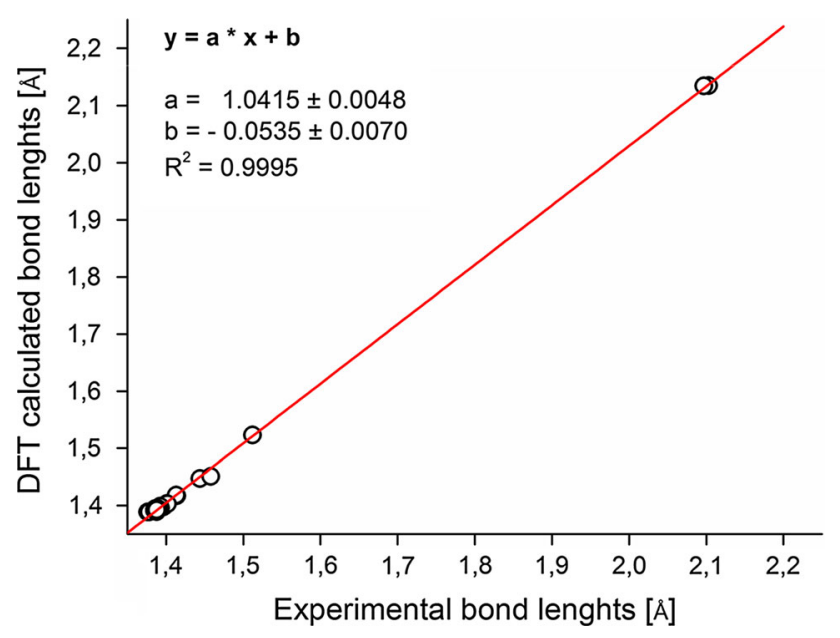

Fig. 3 Linear correlation between theoretical (predicted at B3LYP/6$311++\mathrm{G}(3 \mathrm{df}, 2 \mathrm{pd})$ level, and $6-311 \mathrm{G}^{* *}$ for iodine atom) and experimental bond lengths for 9-benzyl-3,6-diiodo-9H-carbazole

collected for the studied carbazole derivative and for several related compounds. For a direct reference of aromaticity, we show the corresponding NICS values for benzene, calculated at B3LYP/6-311++G(3df,2pd) level of theory $(-7.81,-10.21$, and -29.88$)$. The calculated NICS indexes prove (confirm) the aromaticity of all rings in the studied compound (see Table 5; Fig. 5).

Interestingly, examining the above results it is evident that the most sensitive marker of aromaticity is NICS $(1)_{\mathrm{zz}}$. Following the theory, that the more negative the NICS value the more aromatic the ring is, it is apparent from Fig. 5 that NICS $(0)$ calculated for pyrrole, $9 H$-carbazole, and 9-benzyl-3,6-diiodo-9H-carbazole predicts more aromatic rings than for benzene. The other two variants NICS(1) and NICS $(1)_{z z}$, however, show a different pattern. Based on NICS $(1)_{z z}$ only the pyrrole ring is more aromatic than benzene in complete contrast to the HOMA index. Also the zz-component of NICS(1) indicates that the addition of the benzyl ring and the two iodine atoms significantly affects the aromaticity of carbazole. In comparison to pristine carbazole, the aromaticity of the benzene rings (A and $\mathrm{C}$ ) of 9-benzyl-3,6-diiodo-9H-carbazole are slightly different. This could reflect the effect of specific twisting of benzyl ring to one of the benzene ring of carbazole moiety. 
Table 4 Comparison of experimental and theoretically calculated ${ }^{13} \mathrm{C}$ NMR chemical shifts (in ppm) at BHandHLYP/ DZP level of theory using scalar ZORA, spin-orbit ZORA, and non-relativistic approaches
Both the carbon shieldings experiencing HALA effect and RMS values are marked using bold font

SR ZORA scalar ZORA, NR non-relativistic

\begin{tabular}{lcccc}
\hline & \multicolumn{2}{l}{ Theoretical calculations } & Experimental data \\
\cline { 2 - 4 } Atom numbering & NR & SR ZORA & SO ZORA & \\
\hline C1, 8 & 112.35 & 112.18 & 112.48 & 111.08 \\
C2, 7 & 137.64 & 137.1 & 137.94 & 134.70 \\
C3, 6 & $\mathbf{1 2 3 . 8 0}$ & $\mathbf{1 2 7 . 8 9}$ & $\mathbf{8 7 . 8 3}$ & $\mathbf{8 2 . 2 3}$ \\
C4, 5 & 131.64 & 131.07 & 132.34 & 129.33 \\
C4A, 5A & 127.21 & 127.12 & 127.38 & 127.74 \\
C8A, 9A & 144.32 & 144.17 & 143.89 & 139.62 \\
C10 & 47.89 & 47.98 & 47.94 & 46.56 \\
C11 & 140.74 & 140.82 & 140.78 & 136.10 \\
C12, 16 & 128.40 & 128.38 & 128.37 & 124.05 \\
C13, 15 & 130.43 & 130.57 & 130.40 & 128.88 \\
C14 & 128.81 & 128.77 & 128.75 & 126.18 \\
RMS & $\mathbf{1 2 . 8 5}$ & $\mathbf{1 4 . 0 4}$ & $\mathbf{3 . 3 4}$ & \\
\hline
\end{tabular}

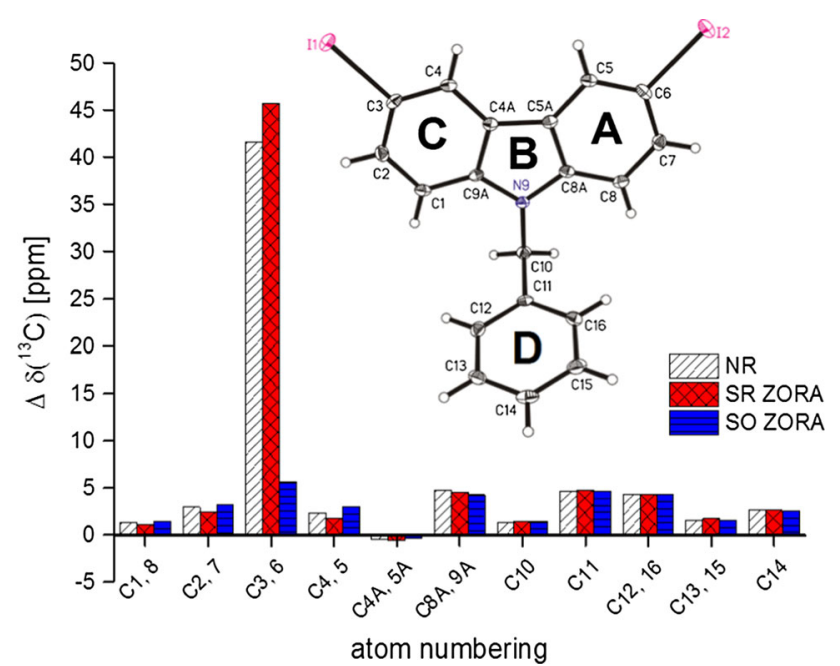

Fig. 4 Deviation of theoretically calculated non-relativistic (NR) and relativistic (scalar ZORA and spin-orbit ZORA) ${ }^{13} \mathrm{C}$ chemical shifts $(\Delta \delta$ in $\mathrm{ppm})$ from experimental data measured for 9-benzyl-3,6diiodo-9H-carbazole in $\mathrm{CDCl}_{3}$ solution at room temperature

\section{Conclusions}

A combined experimental and theoretical study has been performed on 9-benzyl-3,6-diiodo-9H-carbazole. For the first time its crystal structure was determined at $100 \mathrm{~K}$ and the room-temperature ${ }^{13} \mathrm{C} \mathrm{NMR}$ spectrum in $\mathrm{CDCl}_{3}$ solution was measured. The B3LYP/6-311++G(3df,2pd) calculated gas-phase geometry was close (not identical) to the X-ray measured structure in the solid state. The observed I..I contact distances in the crystal structure were 3.9558(3) ^ and no H-bonding was observed.

It was essential to employ the relativistic SO ZORA approach in the chemical shift calculations to reproduce the experimental chemical shift of carbons C3 and C6 (a very large HALA effect of -42 ppm was calculated). Finally, we observed a good linear correlation between experimental and theoretically predicted structural and NMR parameters.

The aromaticity of individual rings was determined by calculations of structural (HOMA) and magnetic (NICS)
Table 5 Comparison of HOMA and selected NICS values for individual rings in 9-benzyl-3,6-diiodo-9Hcarbazole with benzene, pyrrole, and $9 \mathrm{H}$-carbazole

For the labeling of the rings see
Fig. 1

a Values taken from Ref. [48]

\begin{tabular}{lllccc}
\hline Compound & Ring & HOMA & NICS $(0)$ & NICS $(1)$ & NICS $(1)_{\text {zz }}$ \\
\hline 9-Benzyl-3,6-diiodo-9H-carbazole & A & 0.962 & -9.93 & -9.45 & -26.68 \\
& B & 0.446 & -9.18 & -7.66 & -21.62 \\
& C & 0.960 & -8.40 & -8.65 & -24.22 \\
& D & 0.996 & -7.96 & -9.55 & -21.97 \\
$9 H$-Carbazole $^{\mathrm{a}}$ & $\mathrm{A}$ & 0.919 & -12.95 & - & - \\
& $\mathrm{B}$ & 0.679 & -10.24 & - & - \\
$9 H-$-Carbazole & $\mathrm{C}$ & 0.919 & -12.95 & - & - \\
& $\mathrm{A}$ & - & -9.18 & -10.48 & -1.46 \\
& $\mathrm{~B}$ & - & -8.80 & -8.47 & -1.20 \\
Pyrrole & $\mathrm{C}$ & - & -9.18 & -10.48 & -1.46 \\
Benzene & & 0.772 & -13.47 & -10.26 & -32.10 \\
\hline
\end{tabular}




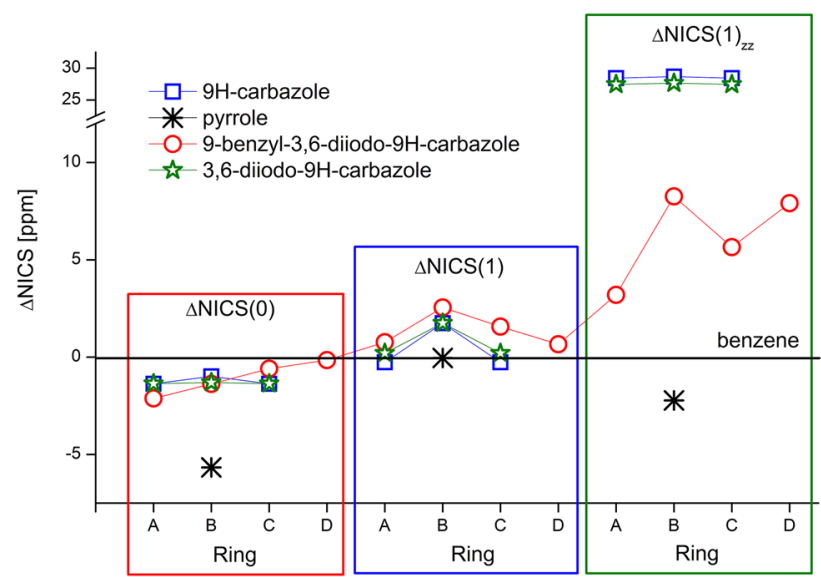

Fig. 5 B3LYP/6-311++G(3df,2pd) calculated differences ( $\Delta$ NICS) in aromatic indices for different rings of pyrrole, $9 H$-carbazole and 9-benzyl-3,6-diiodo-9H-carbazole and 3,6-diiodo-9H-carbazole (benzene was used as reference model for the $\triangle$ NICS indices)

indexes. The most aromatic ring was the benzyl unit $($ HOMA $=0.996)$. The least aromatic was the pyrrolic ring $($ HOMA $=0.446)$. The calculated NICS indexes showed all rings also to be aromatic, but there were significant differences in the predictions of the HOMA and NICS aromaticity indices for the individual rings.

Acknowledgments K. Radula-Janik is a recipient of a $\mathrm{Ph} . \mathrm{D}$. scholarship under a project financed out of the European Social Fund. Teobald Kupka, Zdzisław Daszkiewicz, Krzysztof Ejsmont and Klaudia Radula-Janik were also supported by the Faculty of Chemistry, University of Opole (Grants No. 8/WCH/2014-S, 1/WCH/2014$\mathrm{S}, 7 / \mathrm{WCH} / 2014-\mathrm{S}$ and $12 / \mathrm{WCH} / 2014-\mathrm{M})$. The calculation facilities and software in the Supercomputing and Networking Center ACK CYFRONET AGH in Krakow (Grant No. MNiSW/SGI3700/ UOpolski/061/2008) and at the Supercomputing and Networking Center in Wrocław are also acknowledged. Stephan P.A. Sauer acknowledges support from DCSC and the Lundbeck foundation.

Open Access This article is distributed under the terms of the Creative Commons Attribution License which permits any use, distribution, and reproduction in any medium, provided the original author(s) and the source are credited.

\section{References}

1. Moerner WE, Silence SM (1994) Polymeric photorefractive materials. Chem Rev 94(1):127-155

2. Zhang Y, Hokari H, Wada T, Shang Y, Marder SM, Sasabe H (1997) Synthesis of $N$-vinylcarbazole derivatives with acceptor groups. Tetrahedron Lett 38:8721-8722

3. Morin J-F, Leclerc M, Adès D, Siove A (2005) Polycarbazoles: 25 years of progress. Macromol Rapid Commun 26:761-778

4. Burroughes JH, Bradley DDC, Brown AR, Marks RN, MacKay K, Friend RH, Burn PL, Holmes AB (1990) Light-emitting diodes based on conjugated polymers. Nature 347:539-541

5. Meerholz K, Volodin LB, Sandalphon BK, Peyghambarian N (1994) A photorefractive polymer with high optical gain and diffraction efficiency near $100 \%$. Nature 71:497-500
6. Wang Y (1996) Kirk-Othmer (4th ed) Encyclopedia of chemical technology, vol 18. Wiley, New York, p 837

7. Wang G, Qian S, Xu J, Wang W, Liu X, Lu X, Li F (2000) Enhanced photovoltaic response of PVK/C60 composite films. Phys Part B 279:116-119

8. Grazulevicius JV, Strohriegl P, Pielichowski J, Pielichowski K (2003) Carbazole-containing polymers: synthesis, properties and applications. Prog Polym Sci 28:1297-1353

9. Pearson JH, Stolka M (1981) Polymer monographs, vol 6. Gordon and Breach, New York

10. Stolka M (1988) Encyclopaedia of Polymer Science and Engineering, vol 11. Wiley, New York

11. Boudreault PLT, Beaupré S, Leclerc M (2010) Polycarbazoles for plastic electronics. Polym Chem 1:127-136

12. Beaupré S, Boudreault PLT, Leclrec M (2010) Solar-energy production and energy-efficient lighting: photovoltaic devices and white-light-emitting diodes using poly(2,7-fluorene), poly(2,7-carbazole), and poly(2,7-dibenzosilole) derivatives. Adv Mater 22:E6-E27

13. Li J, Grimsdale AC (2010) Carbazole-based polymers for organic photovoltaic devices. Chem Soc Rev 39:2399-2410

14. Morin J-F, Leclerc M (2002) 2,7-Carbazole-based conjugated polymers for blue, green, and red light emission. Macromolecules 35:8413-8417

15. Radula-Janik K, Kupka T, Ejsmont K, Daszkiewicz Z, Sauer SPA (2013) Halogen effect on structure and 13C NMR chemical shift of 3,6-disubstituted-N-alkyl carbazoles. Magn Reson Chem 51:630-63516

16. Mandowska E, Mandowski A, Tsvirko M (2009) Photoluminescence of epoxy resin modified by carbazole and its halogen derivative at $82 \mathrm{~K}$. Opt Mater 31:1867-1869

17. Bonesi SM, Erra-Balsells R (2001) Electronic spectroscopy of carbazole and $\mathrm{N}$ - and $\mathrm{C}$-substituted carbazoles in homogeneous media and in solid matrix. J Lumin 93:51-74

18. Safoula G, Napo K, Bernede JC, Touhri S, Alimi K (2001) Electrical conductivity of halogen doped poly(N-vinylcarbazole) thin films. Eur Polym J 37:843-849

19. Lampert H, Mikenda W, Karpfen A, Kaehlig H (1997) NMR shieldings in benzoyl and 2-hydroxybenzoyl compounds. Experimental versus GIAO calculated data. J Phys Chem A 101:9610-9617

20. Keeler J (2011) Understanding NMR spectroscopy, 2nd edn. J. Wiley \& Sons, Chichester

21. Berger S, Braun S (2004) 200 and more NMR experiments: a practical course. Wiley-VCH, Weinheim, p 838

22. Jaroszewska-Manaj J, Maciejewska D, Wawer I (2000) Multinuclear NMR study and GIAO-CHF calculations of two quinoacridinium salts. Magn Reson Chem 38:482-485

23. Barfiled M, Fagerness P (1997) Density functional theory/GIAO studies of the ${ }^{13} \mathrm{C},{ }^{15} \mathrm{~N}$ and ${ }^{1} \mathrm{H}$ NMR chemical shifts in aminopirymidines and aminobenzenes: relationships to electron densities and amine group orientations. J Am Chem Soc 119:8699-8711

24. Kupka $\mathrm{T}$ (2009) Convergence of $\mathrm{H}_{2} \mathrm{O}, \mathrm{H}_{2}, \mathrm{HF}, \mathrm{F}_{2}$ and $\mathrm{F}_{2} \mathrm{O}$ nuclear magnetic shielding constants and indirect nuclear spinspin coupling constants (SSCCs) using segmented contracted basis sets XZP, polarization-consistent pcS-n and pcJ-n basis sets and $\mathrm{BHandH}$ hybrid density functional. Magn Reson Chem 47:959-970

25. Kupka T, Stachów M, Nieradka M, Kaminsky J, Pluta T (2010) Convergence of nuclear magnetic shieldings in the Kohn-Sham limit for several small molecules. J Chem Theor Comput 6:1580-1589

26. Wolinski K, Hilton JF, Pulay P (1990) Efficient implementation of the gauge-independent atomic orbital method for NMR chemical shift calculations. J Am Chem Soc 112:8251-8260 
27. Lee C, Yang W, Parr RG (1988) Development of the ColleSalvetti correlation-energy formula into a functional of the electron density. Phys Rev B 37(2):785-789

28. Becke AD (1988) Density-functional exchange-energy approximation with correct asymptotic behavior. Phys Rev A 38:3098-3100

29. Becke AD (1993) A new mixing of Hartree-Fock and local density-functional theories. J Chem Phys 98:1372-1377

30. Erra-Balsells R (1988) 13C NMR spectra of substituted carbazoles and azacarbazoles ( $\beta$-carbolines). Magn Reson Chem 26(12):1109-1112

31. Al-Sultani KTA (2010) Synthesis and evaluation of the biological activity for some carbazole derivatives. J Al-Nahrain Univ 13:31-38

32. Claramunt RM, Cornago P, Sanz D, Santa-MaríaMD, FocesFoces C, Alkorta I, Elguero J (2002) 1-Benzoylazoles: an experimental (NMR and crystallography) and theoretical study. J Mol Struct 605:199-212

33. Kupka T, Pasterna G, Jaworska M, Karali A, Dais P (2000) GIAO NMR calculations for carbazole, and its $N$-methyl and $N$-ethyl derivatives. Comparison of theoretical and experimental 13C chemical shifts. Magn Reson Chem 38:149-155

34. Pyykkö P, Görling A, Rösch N (1987) A transparent interpretation of the relativistic contribution to the NMR heavy atom chemical shift'. Mol Phys 61:195-205

35. Malkina OL, Schimmelpfennig B, Kaupp M, Hess BA, Chandra P, Wahlgren U, Malkin VG (1998) Spin-orbit corrections to NMR shielding constants from density functional theory. How important are the two-electron terms? Chem Phys Lett 296:93-104

36. Komorovský S, Repiský M, Malkina OL, Malkin VG (2010) Fully relativistic calculations of NMR shielding tensors using restricted magnetically balanced basis and gauge including atomic orbitals. J Chem Phys 132:154101

37. Autschbach J, Ziegler T (2002) Relativistic computation of NMR shieldings and spin-spin coupling constants. Encyklopedia of Nuclear Magnetic Resonance, vol 9. J. Wiley \& Sons, Chichester, pp 306-323

38. Kaupp M, Malkin VG, Malkina OL, Salahub DR (1995) Calculation of ligand NMR-chemical shifts in transition-metal complexes using ab initio effective-core potentials and density functional theory. Chem Phys Lett 235:382-388

39. Kaupp M, Malkina OL (1998) Ab initio ECP/DFT analysis of $13 \mathrm{C}$ and $1 \mathrm{H}$ chemical shifts and bonding in mercurimethanes and organomercury hydrides: the role of scalar relativistic. SpinOrbit Substit Eff J Chem Phys 108:3648-3659

40. Kaupp M (1996) NMR chemical-shift anomaly and bonding in piano-stool carbonyl and related complexes. An ab initio ECP/ DFT study. Chem Eur J 2:348-358

41. Arcisauskaite V, Melo JI, Hemmingsen L, Sauer SPA (2011) Nuclear magnetic resonance shielding constants and chemical shifts in linear $199 \mathrm{Hg}$ compounds: a comparison of three relativistic computational methods. J Chem Phys 135:044306-044311

42. Wodyński A, Gryff-Keller A, Pecul M (2013) The influence of a presence of a heavy atom on $13 \mathrm{C}$ shielding constants in organomercury compounds and halogen derivatives. J Chem Theory Comput 9:1909-1917

43. Chang C, Pelissier M, Durand P (1986) Regular two-component pauli-like effective Hamiltonians in dirac theory. Phys Scr 34:394-404

44. Van Lenthe E, Baerends EJ, Snijders JG (1993) Relativistic regular two-component Hamiltonians. J Chem Phys 99:4597-4610

45. Wolff SK, Ziegler T, van Lenthe E, Baerends EJ (1999) Density functional calculations of nuclear magnetic shieldings using the zeroth-order regular approximation (ZORA) for relativistic effects: ZORA nuclear magnetic resonance. J Chem Phys 110:7689-7698

46. Russo TV, Martin RL, Hay PJ (1995) Effective core potentials for DFT calculations. J Phys Chem 99(47):17085-17087

47. Wodyński A, Pecul M (2014) The influence of a presence of a heavy atom on the spin-spin coupling constants between two light nuclei in organometallic compounds and halogen derivatives. J Chem Phys 140(2):024319

48. Poater J, García-Cruz I, Illas F, Solà M (2004) Discrepancy between common local aromaticity measures in a series of carbazole derivatives. Phys Chem Chem Phys 6:314-318

49. Kruszewski J, Krygowski TM (1972) Definition of aromaticity basing on the harmonic oscillator model. Tetrahedron Lett 13(36):3839-3842

50. Krygowski TM (1993) Crystallographic studies of inter- and intramolecular interactions reflected in aromatic character of.pi.electron systems. J Chem Inf Comput Sci 33:70-78

51. PVR Schleyer, Maerker C, Dransfield A, Jiao H, van Eikema Hommes NJR (1996) Nucleus-independent chemical shifts: a simple and efficient aromaticity probe. J Am Chem Soc 118:6317-6318

52. Chuang C-N, Chuang H-J, Wang Y-X, Chen S-H, Huang J-J, Leung M-K, Hien K-H (2012) Polymers with alkyl main chain pendent biphenyl carbazole or triphenylamine unit as host for polymer light emitting diodes. Polymer 53(22):49834992

53. CrysAlis CCD and CrysAlis RED. Oxford Diffraction (2008) Oxford Diffraction Ltd, Abingdon. (Versions 1.171.32.29 ed)

54. Sheldrick GM (2008) A short history of SHELX. Acta Cryst A64:112-122

55. Cambridge Crystallographic Data Centre (CCDC) 12 Union Road C, CB21EZ, UK

56. Stephens PJ, Devlin FJ, Chabalowski CF, Frisch MJ (1994) Ab initio calculation of vibrational absorption and circular dichroism spectra using density functional force fields. J Phys Chem 98:11623-11627

57. Frisch MJ, G. W. Trucks, H. B. Schlegel, G. E. Scuseria, M. A. Robb, J. R. Cheeseman, G. Scalmani, V. Barone, B. Mennucci, G. A. Petersson, H. Nakatsuji, M. Caricato, X. Li, H. P. Hratchian, A. F. Izmaylov, J. Bloino, G. Zheng, J. L. Sonnenberg, M. Hada, M. Ehara, K. Toyota, R. Fukuda, J. Hasegawa, M. Ishida, T. Nakajima, Y. Honda, O. Kitao, H. Nakai, T. Vreven, J. A. Montgomery J, J. E. Peralta, F. Ogliaro, M. Bearpark, J. J. Heyd, E. Brothers, K. N. Kudin, V. N. Staroverov, R. Kobayashi, J. Normand, K. Raghavachari, A. Rendell, J. C. Burant, S. S. Iyengar, J. Tomasi, M. Cossi, N. Rega, J. M. Millam, M. Klene, J. E. Knox, J. B. Cross, V. Bakken, C. Adamo, J. Jaramillo, R. Gomperts, R. E. Stratmann, O. Yazyev, A. J. Austin, R. Cammi, C. Pomelli, J. W. Ochterski, R. L. Martin, K. Morokuma, V. G. Zakrzewski, G. A. Voth, P. Salvador, J. J. Dannenberg, S. Dapprich, A. D. Daniels, O. Farkas, J. B. Foresman, J. V. Ortiz, J. Cioslowski, Fox DJ (2009) Gaussian 09, Revision A.02. Gaussian, Inc., Wallingford

58. Versluis L, Ziegler T (1988) The determination of molecular structures by density functional theory. The evaluation of analytical energy gradients by numerical integration. J Chem Phys 88:322-328

59. ADF2012 S, theoretical chemistry, Vrije Universiteit, Amsterdam, 2012. http://www.scm.com

60. Chesnut DB, Moore KD (1989) Locally dense basis sets for chemical shift calculations. J Comput Chem 10:648-659

61. Bondi A (1964) Van der Waals volumes and radii. J Phys Chem 68:441-451

62. Batsanov SS (2001) Van der Waals radii of elements. Inorg Mater $37: 871-885$ 
63. Batsanov SS (2001) Van der Waals radii of elements. Neorg Mater 37:1031-1046

64. Allen FH, Kennard O, Watson DG (1987) Tables of bond lengths determined by X-ray and neutron diffraction. Part I: bond lengths in organic compounds. J Chem Soc Perk Trans II:S1-S19
65. Uludag N, Ates M, Tercan B, Ermis E, Hökelek T (2010) 9-Benzyl-9H-carbazole. Acta Cryst E 66:o1077(Suppl 1-Suppl 10)

66. Krygowski TM, Cyrański MK (2001) Structural aspects of aromaticity. Chem Rev 101:1385-1420 